\title{
Study on the Mechanism of a Carrier-based Engine Parts' Performance Decline and Its Impact on the Whole Engine Performance
}

\author{
Wu Heng ${ }^{1, a}$, Li Benwei ${ }^{1}$, Zhao Shufan ${ }^{1}$ and Wang Yonghua ${ }^{1}$ \\ ${ }^{1}$ Aviation Foundation College, Naval Aviation University, Yantai Shandong 264001, China
}

\begin{abstract}
The technical approach "use - parts' change - engine performance change" has been adopted to study and analyse the gas unit parts' performance changes of an engine after a long time operation. The mechanism of performance decline of the turbine is analysed based on the numerical simulation, the impact of components' performance decline on overall engine performance is studied and the correlation analysis is carried out. The results show that the change of turbine tip clearance, roughness increase and surface change will lead to the enhancement of secondary flow and the increase of influence area, and the turbulence effect is strengthened, resulting in the decrease of turbine circulation capacity and efficiency. The booster ratio of high pressure compressor, the flow capacity of high pressure and low pressure turbines, the flow capacity and efficiency of fan are the major component parameters causing the overall engine performance's degradation. And it also provides theoretical basis for the prevention of engine performance's degradation and online washing of parts and the whole machine.
\end{abstract}

\section{Introduction}

The engine of a navy carrier aircraft should meet the requirements of the escape away for slipping off. Due to the particularity of marine shipborne environment, failure and performance degradation of the engine's components are more serious. The decrease of thrust and other indicators will directly affect the flight safety of the carrier aircraft. Therefore, it is urgent to study the performance degradation mechanism and reasons of the engine and using the corresponding maintenance and repair technology and making a reasonable arrangements for maintenance time to avoid or reduce the performance recession of engine.

A large number of studies on the performance degradation of aircraft engines at home and abroad can be divided into two ways: the first way is studying on the declining laws of engine performance based on the change of whole machine Performance and the second way is studying on the decline mechanism from parts to machine. The abroad research works in this field mainly include the influence of blade roughness and engine manufacturing tolerance on the performance of the engine's turbo and compressor[1-3], the impact of components' performance degradation on whole engine performance[4-5] as well as the issues of engine performance degradation and control strategy

\footnotetext{
${ }^{\mathrm{a}}$ Corresponding author: wuheng89810@163.com
} 
optimization[6-7]. In recent years, component performance change process has been analysed by means of experimental and numerical analysis at home[8-12].

In this paper, the technical approach "use - parts' change - engine performance change" has been adopted to study and analyse the gas unit parts' performance changes of an engine after running $100 \mathrm{~h}$. Based on the numerical simulation, the performance degradation mechanism of the fan and turbine are analysed, the influence of component performance degradation on the whole machine performance is studied and the correlation analysis is carried out, and the characteristic parameters of the gas unit parts are extracted.

\section{Changes in engine gas unit components after prolonged use}

Through the investigation and research, various data of a carrier-based aircraft engine after running $100 \mathrm{~h}$ is obtained. After a long period of operation, the engine has occurred parts wear, cracks, flow channel gap increases, pollution, resulting in a certain degree of engine performance attenuation, this article analyses the possible performance degradation induced factors of the engine from the inspection of the engine gas unit components.

Through the observation, it is found that after a long period operation, there is no significant change in the appearance of the air intake casing, but the oxide layer of adjustable leaves' micro-arc is peeled off, and also there are local drum phenomenon, as is shown in Figure 1, the peeling off of the adjustable blade protective layer and local drum phenomenon directly affect the smoothness of the airflow channel, while the leaves' material is aluminium alloy so that salt spray corrosion is relatively poor, in ship-borne conditions the adjustable blade protection layer peeling off will cause further corrosion, change the fan flow conditions, affecting the overall performance of the fan.

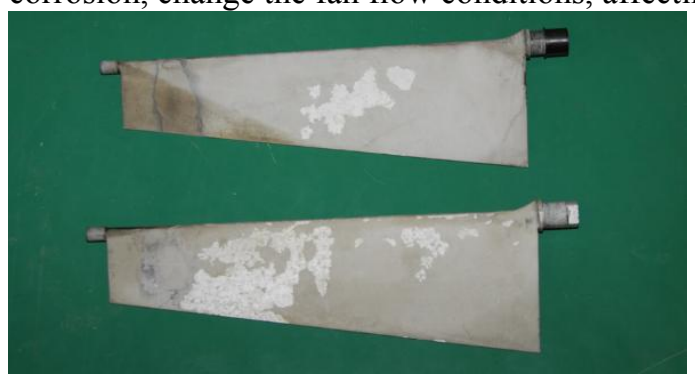

Figure 1. Adjustable leaf coating to peel off

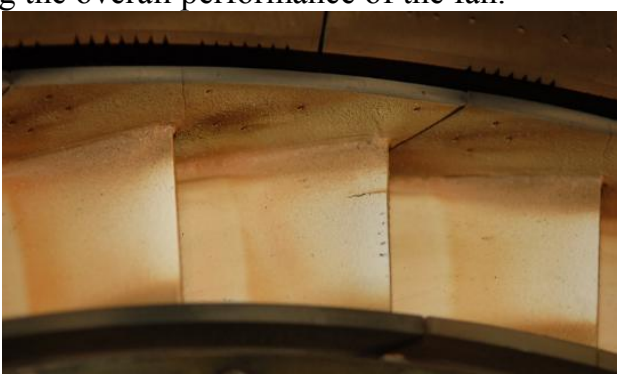

Figure 2. High pressure turbine guided blade fouling

Table 1. Main size parameters of high pressure turbine

\begin{tabular}{|c|c|c|c|c|}
\hline $\begin{array}{c}\text { Component name } \\
\text { and drawing } \\
\text { number }\end{array}$ & Test items & $\begin{array}{c}\text { Drawing } \\
\text { requirements }\end{array}$ & $\begin{array}{c}\text { Actual } \\
\text { inspection }\end{array}$ & Conclusion \\
\hline On the component & $\begin{array}{c}\text { Measure the tip } \\
\text { diameter of the } \\
\text { working blades }\end{array}$ & $\Phi 727.2-726.9$ & $\Phi 726.63$ & unqualified \\
\hline The first level & $\Phi 556.1-555.6$ & $\Phi 556.02$ & qualified \\
\hline $\begin{array}{c}\text { Outer diameter } \\
\text { dimension of turbine } \\
\text { front seal plate }\end{array}$ & $\begin{array}{c}\text { The second } \\
\text { level }\end{array}$ & $\Phi 561.4-560.8$ & $\Phi 561.30$ & qualified \\
\hline & The third level & $\Phi 566.6-565.9$ & $\Phi 566.58$ & qualified \\
\hline
\end{tabular}




\begin{tabular}{|c|c|c|c|c|} 
& $\begin{array}{c}\text { The fourth } \\
\text { level }\end{array}$ & $\Phi 571.8-571.0$ & $\Phi 571.86$ & unqualified \\
\hline
\end{tabular}

The surface properties of the high-pressure compressor blades and the performance of the main combustion chamber have no obvious change. The high-pressure turbine guide blades at the rear of the main combustion chamber have slight fouling and the roughness increases, as is shown in Figure 2. The trailing edge of the guide blade has a crack, the longest is up to $8 \mathrm{~mm}$ (Specified $\ngtr 6 \mathrm{~mm}$ ). The high pressure turbine rear baffle is subjected to fluorescence permeation detection, and no crack defects are found, it is found that there is a lot of oil on the high pressure turbine disk by decomposition. The correlation measurement results in the process of high pressure turbine decomposition are shown in Table 1.

The oil on the high-pressure turbine wheel increases the possibility of further fouling, profile change, and roughness increase in the follow-up process. The tip diameter of the component is too small, it indicates that after a long operation the high pressure turbine blade tip gap is too large, which will increase the leakage, reduce the efficiency of the turbine. The low pressure turbine rotor uses a crowned blade, which can effectively reduce leakage of the working wheel, low-pressure turbine performance will not change significantly. Therefore, this paper mainly analyses the performance degradation mechanism of fan and high pressure turbine components.

\section{Performance degradation mechanism of turbine components based on numerical simulation}

The performance test of engine components is often costly, especially the blade angle adjustment is not in place, the roughness increases, the leaf type and other components performance analysis in nonnormal conditions are very difficult, therefore in this paper how the change of parts' surface and surface conditions caused by the environment and the use of time will affect the component performance is analysed through CFD technology. Due to space limitations, a brief description of the numerical simulation method is given in this paper.

\subsection{Numerical simulation method}

\subsubsection{Reconstruction and correction of geometric model}

For the fan, compressor, turbine and other components' leaf type data is the engine's core secrets, through the investigation and research it can only get the basic geometric parameters rather than detailed aerodynamic design parameters of the first level of the fan and high pressure turbine. In this paper, GAMBIT is used to reconstruct the local linearity of each blade, and the geometrical information of GAMBIT is transformed into generalized geometric file IGES to the subsequent BLADEGEN processing software. Reverse design of the turbine blade is used to reconstruct the geometry model of the fan and turbine, the blade design pattern is transformed from "angle-thickness" to "suction surface-pressure surface" mode, and then the leaf type correction is realized by adjusting the pressure surface profile. The reconstructed high pressure turbine blade model is shown in Figure 3. 

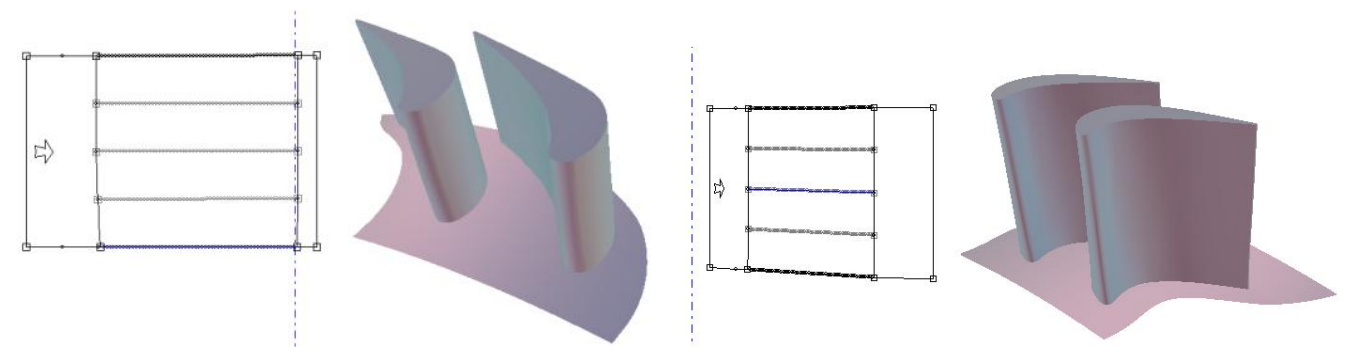

Figure 3. Reconstructed high pressure turbine blades

\subsubsection{Calculate regions, grids, and theoretical models}

Turbine calculation area is " 0 -level adjustable deflector blade +1 -stage rotor +1 level stator", in order to ensure the calculation accuracy, select the same fan scale for each level of calculation area, multichannel calculation is used. Each calculation channel is "OH-shaped" mesh, and the non-matching grid interface is used for the moving leaves. Using the time-averaged turbulence model to calculate the specific heat flow field of variable specific heat:

$$
\begin{aligned}
& \frac{\partial \rho}{\partial t}+\frac{\partial}{\partial x_{i}}\left(\rho u_{i}\right)=0 \\
& \frac{\partial}{\partial t}\left(\rho u_{i}\right)+\frac{\partial}{\partial x_{j}}\left(\rho u_{i} u_{j}\right)=-\frac{\partial p}{\partial x_{i}}+\frac{\partial}{\partial x_{j}}\left[\mu_{e f f}\left(\frac{\partial u_{j}}{\partial x_{i}}+\frac{\partial u_{i}}{\partial x_{j}}\right)\right]-\frac{2}{3} \frac{\partial}{\partial x_{j}}\left[\mu_{e f f}\left(\frac{\partial u_{i}}{\partial x_{i}}\right)\right] \\
& \frac{\partial}{\partial t}(\rho E)+\frac{\partial}{\partial x_{i}}\left(\rho u_{i} E\right)=-\frac{\partial p u_{i}}{\partial x_{i}}+\frac{\partial}{\partial x_{j}}\left[\mu_{e f f} u_{i}\left(\frac{\partial u_{j}}{\partial x_{i}}+\frac{\partial u_{i}}{\partial x_{j}}\right)\right]-\frac{2}{3} \frac{\partial}{\partial x_{j}}\left[\mu_{e f f} u_{i}\left(\frac{\partial u_{i}}{\partial x_{i}}\right)\right]+\frac{\partial}{\partial x_{j}}\left[k_{e f f}\left(\frac{\partial T}{\partial x_{j}}\right)\right] \\
& p=\rho R T
\end{aligned}
$$

The turbulence effect of the flow is calculated by using the $k-\omega_{\text {turbulence model: }}$

$$
\begin{aligned}
& \frac{\partial}{\partial t}(\rho k)+\frac{\partial}{\partial x_{i}}\left(\rho u_{i} k\right)=\frac{\partial}{\partial x_{j}}\left(\Gamma_{k} \frac{\partial k}{\partial x_{j}}\right)+G_{k}-Y_{k}+S_{k} \\
& \frac{\partial}{\partial t}(\rho \omega)+\frac{\partial}{\partial x_{i}}\left(\rho u_{i} \omega\right)=\frac{\partial}{\partial x_{j}}\left[\Gamma_{\varepsilon}\left(\frac{\partial \omega}{\partial x_{j}}\right)\right]+G_{\omega}-Y_{\omega}+S_{\omega}
\end{aligned}
$$

Turbulent viscosity: $\mu_{t}=\alpha^{*} \frac{\rho k}{\omega}$ among them: $\mu_{\text {eff }}=\mu+\mu_{t}$.

The turbine is a typical pressure gradient flow field, so the improved wall function is used, and the wall grid is locally encrypted. The effect of fouling and corrosion on the blade and airflow channel is replaced by roughness equivalent, other import and export conditions are given in accordance with the design documents. The second-order finite volume method is used to solve the control equations, and the computational complexity and the calculation precision are taken into account. The coupling effect of the static and dynamic regions is calculated by the mixed plane method.

\subsection{Simulation results analysis}

The calculation results of the turbine flow field in design point are discussed. There are obvious secondary tip flow in the two conditions of the gap clearance and the excess, for the smaller gap of the leaves, only more than $90 \%$ of the leaf height has been influenced by the secondary flow, the area of the secondary flow increases when the gap is large. The secondary flow of the large tip gap creates a large low velocity zone at the tail of the turbine blade, affecting gas deflection and expansion, the 
secondary flow schematic diagram of a large turbine blade tip clearance is shown in Figure 4. In addition, the Mach number distribution indicates that the turbine is a guide supercritical highcompound turbine, both guide blade fouling and roughness increase will reduce its flow capacity, Mach number distribution of a large turbine blade tip clearance ( $90 \%$ leaf height) is shown in Figure 5.

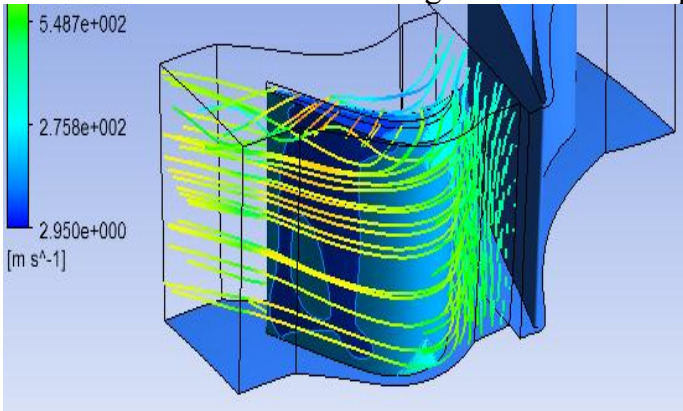

Figure 4. The secondary flow schematic diagram of a large turbine blade tip clearance
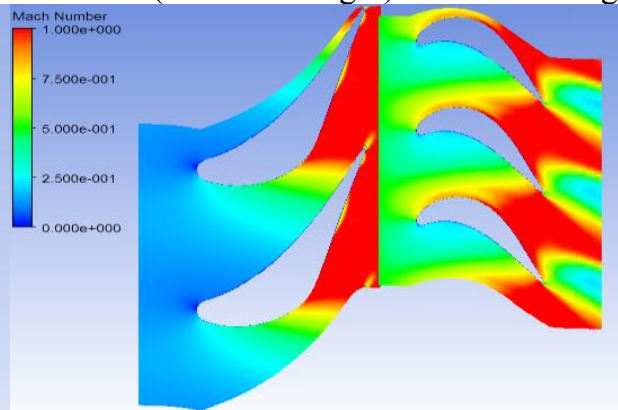

Figure 5. Mach number distribution of a large turbine blade tip clearance ( $90 \%$ leaf height)

Therefore, the change of turbine tip clearance, roughness increase and surface change will lead to the enhancement of secondary flow and the increase of influence area, and the turbulence effect is strengthened, resulting in the decrease of turbine circulation capacity and efficiency. When the fouling caused the change of leaf shape, turbine performance degradation is more serious.

\section{Analysis on the effect of component performance decline on overall machine performance}

\subsection{Analysis on the law of change of whole machine performance}

After a long period of operation, the engine performance changes mainly reflects in thrust drop and fuel consumption increases (where the fuel consumption is converted to the same thrust fuel consumption), the acceleration performance of the engine decreases slightly, but not obvious. Figure 6 $\sim$ Figure 8 show the comparison of a variety of engine test parameters before and after a long time running.
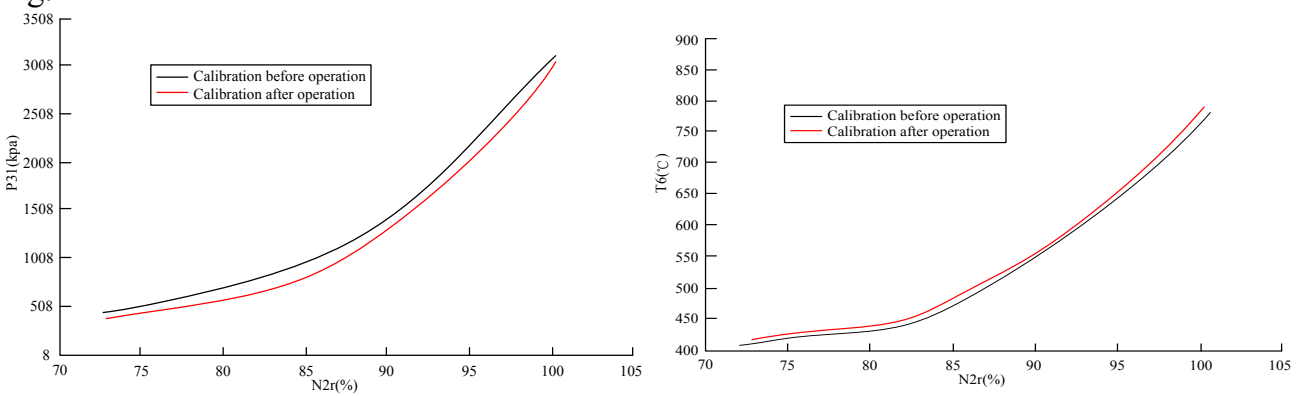

Figure 6. Comparison of engine total boost ratio Figure 7. Comparison of engine turbine rear temperature

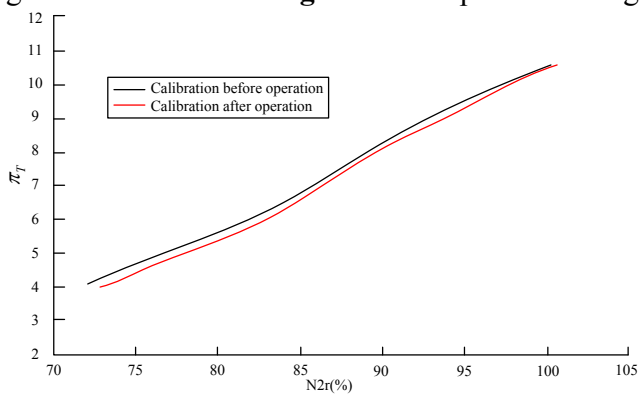


Figure 8. Comparison of turbo expansion ratio

As is shown in Figure 6 to Figure 8, after a long period of operation, the engine fan, high pressure compressor inlet guide vane, adjustable stator blade error, and fan blade surface roughness increases, may cause the degradation of efficiency and boost performance of the engine fan and compressor, also the degradation of the engine's total boost performance. The increase of turbine blade roughness and tip clearance may cause the decrease of turbine efficiency and the turbo expansion ratio, and increase of the exhaust temperature.

\subsection{Correlation analysis of component characteristic parameters and engine performance}

The calculation of engine performance parameters will produce some errors by using the aerodynamic thermodynamic performance model of a kind of carrier-based engine. However, the sensitivity and trend analysis are mainly carried out in this paper, so the model meets the requirements.

When the engine is running for a long time, the characteristic parameters of the rotating parts are susceptible to changes and affect the target performance parameters of the engine. Therefore, the high pressure compressor flow $W_{3}$, high pressure compressor efficiency $\eta_{c H}$, high pressure compressor boost ratio $\pi_{c H}$, fan flow $W_{a 22}$, fan efficiency $\eta_{c L}$, fan pressure ratio $\pi_{c L}$, high pressure turbine flow $W_{s t 45}$, high pressure turbine efficiency $\eta_{T H}$, low pressure turbine flow $W_{s t 5}$, low pressure turbine efficiency $\eta_{T L}$ are selected as the influencing factors for sensitivity analysis. Taking the actual situation and the difficulty of parameter measurement into account, the high pressure compressor outlet pressure $P_{3}$, low pressure turbine outlet temperature $T_{5}$, tail nozzle outlet temperature $T_{8}$, engine thrust $F$, and fuel consumption $s f c$ are selected as the affected target performance parameters. Changes in the performance parameters of the engine components can cause changes in the performance of the components and thus affect the overall performance of the engine. However, different component characteristic parameters have different effects on different overall performance parameters. The correlation analysis method can be used to analyse the influence between parameters. Define the correlation coefficients as:

$$
r_{i j}=|\Delta j / \Delta i|
$$

Among them, $\Delta j$ represents the amount of change of the $j$ th target performance parameter and $\Delta i$ represents the amount of change of the $i$ th component characteristic parameter.

Firstly calculate the correlation coefficient between the engine component characteristic parameter and the target performance parameter. In this paper, a single parameter perturbation method is used. Reduce the component characteristic parameters by $2 \%$ successively, while keeping the remaining part characteristics unchanged, calculate the overall performance changes of the engine. For the correlation analysis, the correlation coefficient is normalized and the results are shown in Table 2.

$$
\overline{r_{i j}}=r_{i j} / \sqrt{\sum_{k=1}^{10} r_{k j}} \quad(i=1,2, \cdots, 10, j=1,2, \cdots, 5)
$$

Table 2. The correlation coefficient after normalization

\begin{tabular}{|c|c|c|c|c|c|}
\hline$\%$ & $P_{3}$ & $T_{5}$ & $T_{8}$ & $F$ & $s f c$ \\
\hline$W_{a 22}$ & 0.1281 & 0.0175 & 0.2017 & 0.1026 & 0.0821 \\
\hline$\eta_{c L}$ & 0.1052 & 0.1926 & 0.2456 & 0.0714 & 0.0372 \\
\hline$\pi_{c L}$ & 0.2205 & 0.0016 & 0.0016 & 0.0050 & 0.0805 \\
\hline$W_{3}$ & 0.0166 & 0.0394 & 0.0024 & 0.0585 & 0.0124 \\
\hline
\end{tabular}




\begin{tabular}{|l|l|l|l|l|l|}
$\eta_{c H}$ & 0.0429 & 0.0009 & 0.0014 & 0.0010 & 0.0009 \\
\hline$\pi_{c H}$ & 0.1891 & 0.1295 & 0.0243 & 0.2160 & 0.3491 \\
\hline$W_{s t 45}$ & 0.0833 & 0.0723 & 0.1539 & 0.2301 & 0.2111 \\
\hline$\eta_{T H}$ & 0.1117 & 0.0181 & 0.0821 & 0.1962 & 0.0429 \\
\hline$W_{s t 5}$ & 0.0376 & 0.2527 & 0.1623 & 0.0931 & 0.1831 \\
\hline$\eta_{T L}$ & 0.0650 & 0.2753 & 0.1248 & 0.0260 & 0.0006 \\
\hline
\end{tabular}

Define the sensitivity of the parameters:

$$
k_{i}=\sum_{j=1}^{5} \overline{r_{i j}},(i=1,2, \cdots, 10)
$$

The sensitivity coefficient of each component parameter is shown in Table 3.

Table 3. Sensitivity coefficient

\begin{tabular}{|l|l|l|l|l|l|l|l|l|l|l|}
\hline & $W_{a 22}$ & $\eta_{c L}$ & $\pi_{c L}$ & $W_{3}$ & $\eta_{c H}$ & $\pi_{c H}$ & $W_{s t 45}$ & $\eta_{T H}$ & $W_{s t 5}$ & $\eta_{T L}$ \\
\hline$k$ & 0.5320 & 0.6520 & 0.3092 & 0.1293 & 0.0471 & 0.9080 & 0.7507 & 0.4510 & 0.7288 & 0.4917 \\
\hline
\end{tabular}

The first five component performance parameters which affect the engine performance are: high pressure compressor boost ratio $\pi_{c H}$, low pressure turbine flow $W_{s t 5}$, high pressure turbine flow $W_{s t 45}$, fan efficiency $\eta_{c L}$ and fan flow $W_{a 22}$. Therefore, the prevention of engine performance degradation should start with the prevention of degradation on the engine's air compression system and turbine components performance.

\section{Equations and mathematics Conclusion}

Through the analysis of a carrier-based engine's performance change after prolonged use, the mechanism of performance degradation of fan and turbine are studied, and then the impact of component performance degradation on overall machine performance is analysed. The following conclusions can be drawn:

(1)the change of turbine tip clearance, roughness increase and surface change will lead to the enhancement of secondary flow and the increase of influence area, and the turbulence effect is strengthened, resulting in the decrease of turbine circulation capacity and efficiency. When the fouling caused the change of leaf shape, turbine performance degradation is more serious.

(2)the engine performance degradation mainly reflects in the decrease of thrust, increase of fuel consumption and exhaust temperature, the acceleration performance of the engine decreases slightly. High pressure compressor boost ratio, low pressure turbine flow, high pressure turbine flow, fan efficiency and fan flow are the main component performance parameters which lead to the engine performance degradation. Therefore, the prevention of engine performance degradation should start with the prevention of degradation on the engine's air compression system and turbine components performance. It also provides a theoretical basis for the engine parts and overall machine online washing.

\section{Acknowledgments}

Thanks for the financial support from special funds of Taishan Scholar Project.

\section{References}


1. P Luis, $\mathrm{S}$ Thorsten, The influence of blade roughness on the performance of a vertical axis tidal turbine,IJOME, 17: 136-146(2017).

2. S. S.Talebi, A. M.Tousi,The effects of compressor blade roughness on the steady state performance of micro-turbines,ATE, 115: 517-527(2017).

3. B Marco, B Fabio, S Daniele, Combined experimental and numerical investigations on the roughness effects on the aerodynamic performances of LPT blades,JOTS, 25(1): 32-42(2016).

4. A Castillaa, J Fernándezb, J.M. Montaneroc, Influence of the manufacturing process tolerance on the swirl number of a low-capacity engine,JOMS, 41: 157-164(2016).

5. T Mohammadreza, M Masdi, Z. A. A. Karim,Performance evaluation of a twin-shaft gas turbine engine in mechanical drive service,JOMSAT, 31(2): 937-948(2017).

6. K Vikas, Remaining life related issues being pursued at DRDO for indian air force,PE, 55: 428432(2013).

7. A. T. James, S. L. Jonathan, A foreign object damage event detector data fusion system for turbofan engines,JOAIS, 2(7): 291-308(2005).

8. D Li, W Zhang, M. Z. Ji, Engine gas path performance model modification based ongenetic algorithm,GTXAR, 25(4):46-50(2012).

9. W Tan, X. C. Yu, D Li, Research of engine performance deterioration index forecasting based on CFD,GTT,30(1):48-52(2017).

10. D Li, W Zhang, M. Z. Ji, Numerical study of performance deterioration of engineguide vane and turbine blade,GTT, 28(1):35-41(2015).

11. S Wang, G. H. Wang, Q Han, Compressor performance deterioration caused by blade fouling,JOHEU,35(12):1524-1528(2014).

12. B. W. LI, D Li, W Shen, Research on turbine lamina roughness influence on its performance declination, ACT, 39(5): 26-29(2009). 